\title{
A Study of Commercial Banks Interest Rate Risk Management under Interest Rates Liberalization
}

\author{
Yun Zhou \\ Shanghai University, P.R. China \\ Xiaosong Zheng \\ Shanghai University, P.R. China
}

\begin{abstract}
Interest rate risk emerges with the development of interest rate marketization in China, which makes rate risk management become more and more important. Interest rate risk sensitive gap is one of the most useful management tool to assess and control interest rate risk. This paper uses interest rate sensitive gap model to analyse several Chinese commercial banks' current interest rate risk level and their control over the risks. By conducting a study on four domestic banks in China, it is found that the risk level of state-owned banks is higher than that of joint-stock banks. However, their risk management is weaker comparing to that of the joint-stock banks.
\end{abstract}

Key words: Interest rate marketization; commercial bank; interest rate risk; interest rate sensitive gap

JEL code: G320

\section{Introduction}

China's interest rate marketization formally took place in 1996. The reform promoted the self-pricing power, increased profits, and also made the allocation of loan and deposit rate of the financial institutions more efficient. However, due to the long-term control over interest rate by the Central Bank of China, domestic commercial banks lacked the awareness and experience to manage interest rate risk. The risk management skills lagged far behind foreign banks. Hence, it is a challenge for commercial banks in China to eliminate or even avoid the interest rate risks. Carrying out the interest rate sensitive gap model gives domestic 
commercial banks an opportunity to avoid this risk by predicting the trend of future interest rate, and then reallocate assets and liabilities accordingly. This paper begins with the literature review on interest rate marketization, interest rate risk and interest rate management, especially about interest rate risk sensitive gap model. Next, introducing the interest rate risk effect to commercial banks in China. Finally, applying a study to analyze the interest rate risk level and management skill in local financial institutions by using sensitive gap model, which was followed by a recommendation as conclusion.

\section{Literature review}

\subsection{Interest rate liberalization}

The interest rate risk can be traced back to 1970 that America first implemented the reform, followed by Japan, Korea, Indonesia, Thailand and India. China's interest rate reform started quite late, at the year of 1996, which was twenty-six years lag behind America. Not until 2015 did China finished the reform. He et al. (2017) suggested that Chinese banks profitability had already been improved and risks were lowered, but at the same time, efficiency was also lowered in 2005. It intimated that since 2005 the direction led to a right way of making more profits and cutting down risks in banks, but more reforms ought to be taken in to improve bank efficiency. Fu and Shelage (2006) proposed that during the initial stage of reform state-owned banks performed market power through offering various products. Michael and Peter (2015) divided the liberalization into two different scenarios: partial liberalization and complete liberalization. The aim of the complete liberalization was to revise the misallocation in credit by raising the cost of bank funds. Banks' net interest margin would be narrowed if deposit rates are raised and banks would have pressure on raising lending rates. He et al. (2014) pointed out that deposit rates were likely to be higher, whereas lending rates were not clear. It might rely on the development of financial markets in China. The reason why China's interest rate reform grew slowly is that it raised banks that controlled by the central bank's cost of capital and they could not gain profit margin in the inflexible interest rate system (Wen, 2015). However, Wei and Sampawende (2014) claimed that saving rates would be reduced, consumption would be boosted, and China's growth would be more inclusive under the full marketization of interest rate. Moreover, more competition would occur among banks which was necessary for economic development. Also, Wang et al. (2016) shared the similar point that complete liberalization was regarded as an effective way for commercial banks to stay 
away from high reserve demands. Tung and Shu (2013) stated that the feature of financial reform supplied market clues if a bank was running at an ideal situation, which also explained that a trade-off between bank risks and efficiency were exposed to the government and banks themselves.

\subsection{Interest rate risk in commercial banks}

Afroditi's study (2012) displayed that changes in the macroeconomic environment had a tight connection with the development of the prime market for risk. Angele (2008) defined interest rate risk as a possibility to bring about lose because of interest rate fluctuations. The risk rooted in the imbalance between assets and liabilities. The risk was a common part in the banking business, however, too high-risk rate can lead to the reduction of bank income as well as capital value. According to Basel Committee on Banking Supervision (2004), interest rate risk was divided into four types: basis risk, yield curve risk, optionality risk and re-pricing risk. Jim (2006) defined that the re-pricing risk generated from the fact that the assets and the liabilities were not priced again at the same time. Wolfgang and Geoffrey (1997) tested different classes of banks and made a conclusion that banks with high-risk loans and higher interest rate risks prefer to choose loan and deposit rates to gain higher net interest margins. Tony et al. (2017) suggested that private bank loan growth was more likely to become sensitive to interest rates changes.

\subsection{Interest rate risk management: Interest rate sensitive gap model}

Luminita (2016) indicated that the interest rate risk emerged when temporary placements are financed by the resources in the bank, and the interest expense was equal to the deposits of a bank increase. Reviewing the maturity profile of assets and liabilities regularly was the banks' duty. If any mismatches beyond the acceptable range are found banks ought to start the adjust actions like stop receiving deposits for a special time duration, presented by Krishna and Suprabha in 2014. Anwer et al. (1997) put forward that the interest rate sensitive of net income was the main focus of the interest rate risk management. Interest rate sensitivity was also evident in banking because interest rates showed banks' input and output price. As a result, it is an important indicator to exam whether the operation in banks was healthy or not and is an issue of much interest to managers, regulators and governments (Raj et al. 2005). Augustin and David (2015) thought that the income gap measured the degree to which a 
bank's net interest income was sensitive to the fluctuation of interest rates. Cui (2016) found the unreasonable allocation of medium and long-term assets and liabilities in banking structure by using interest rate sensitive model. However, Mathias et al. (2008) showed that only use gap analysis would underestimate the risks in banks, though it grasped the first re-pricing mismatch and it would not occupy the negative effect of interest rates on assets quality.

\section{Empirical analyses}

\subsection{The effect of interest rate risk on China's commercial banks}

It is true that the reform can allocate the market resource, but commercial banks are forced to bear various risks due to high profit by high deposit and loan margin. Therefore, it is necessary to know this change's influence towards interest rate first. One effect is the interest rate fluctuation caused by interest rate marketization. Once the controlled interest rate is loosened, it will increase rapidly, but then fluctuate irregularly followed by the market. China's deposit and loan rate are knowable during the interest rate control period, so that cost benefit of commercial banks can be decided. However, when the interest rate is loosened, frequent fluctuation of interest rate adds commercial banks' bankrupt risk during the transitory phase. In addition, interest rate marketization narrows deposit and loan interest margin. Deposit and loan are the basic services of commercial banks, which implies that the main source of revenue comes from interest margin. After interest rate marketization, deposit competition will become fiercer. Therefore, banks should expand their source of capital to utilize interest on deposit to attract clients. By contrast, the demand for the loan is still sluggish, which makes banks difficult to raise loan rate.

\subsection{The analyses of interest rate risk level and control ability of China's commercial bank}

This paper selected four commercial bank in China, namely Bank of China (BOC), Industrial and Commercial Bank of China (ICBC), China Merchants Bank (CMB) and China Minsheng Bank (CMBC), as research targets to calculate their interest rate sensitive gap in order to reveal the interest rate risk level and control ability in China's commercial banks. The reason 
to choose BOC and ICBC is that it represents the state-owned bank, while CMB and CMBC represent the small and medium-sized bank. There are two indicators to calculate interest rate sensitive gap model: interest rate sensitive gap to reflect absolute balance and interest rate sensitive coefficient to reflect a relative quantity of interest rate sensitive asset and liability. This paper will mainly use the GAP formula.

$$
\begin{aligned}
& \mathrm{GAP}=\text { IRSA- IRSL (1) } \\
& \mathrm{IRSR}=\text { IRSA/ IRSL (2) }
\end{aligned}
$$

Table 1. The effect towards net interest of commercial banks caused by fluctuation of interest rate Assumption: changes of deposit rate and loan rate remains the same

\begin{tabular}{|l|l|l|l|l|}
\hline \multicolumn{1}{|c|}{ GAP } & \multicolumn{1}{|c|}{ IRSR } & \multicolumn{1}{|c|}{$\begin{array}{c}\text { Variation of } \\
\text { interest rate }\end{array}$} & \multicolumn{1}{|c|}{$\begin{array}{c}\text { Variation of } \\
\text { interest income }\end{array}$} & \multicolumn{1}{|l|}{$\begin{array}{l}\text { Variation of net } \\
\text { interest }\end{array}$} \\
\hline positive & $>1$ & increase & increase & increase \\
\hline positive & $>1$ & decrease & decrease & decrease \\
\hline negative & $<1$ & increase & increase & decrease \\
\hline negative & $<1$ & decrease & decrease & increase \\
\hline zero & $=1$ & increase & increase & $=$ \\
\hline zero & $=1$ & decrease & decrease & $=$ \\
\hline
\end{tabular}

According to the interest rate policy issued by the People's Bank of China, the interest rate was adjusted eight times during five years under the interest rate liberalization. The reform gave financial institutions more chances to price by themselves. The deposit rate had a steady decline rate $0.25 \%$ each year, starting from $3.25 \%$ in 2012 to $1.5 \%$ in 2015 . This action was propitious to reduce commercial banks' financing cost. The trend of debt rate was similar to the deposit rate, with the same decline rate $0.25 \%$ in all of the five reductions in interest rate in 2015, and finally stabled at $4.35 \%$. Commercial banks loosened the requirements of making loans. In other words, the public was more convenient to make loans and more talented people were boosted to start their own business. Both debt and deposit have no 
change in 2013, instead, the central bank canceled the lower floating rate of the debt rate. The percentage of the variances income between loan and deposit rate was declined in the total income. The figure below shows the differences of the debt and deposit rate in five years.

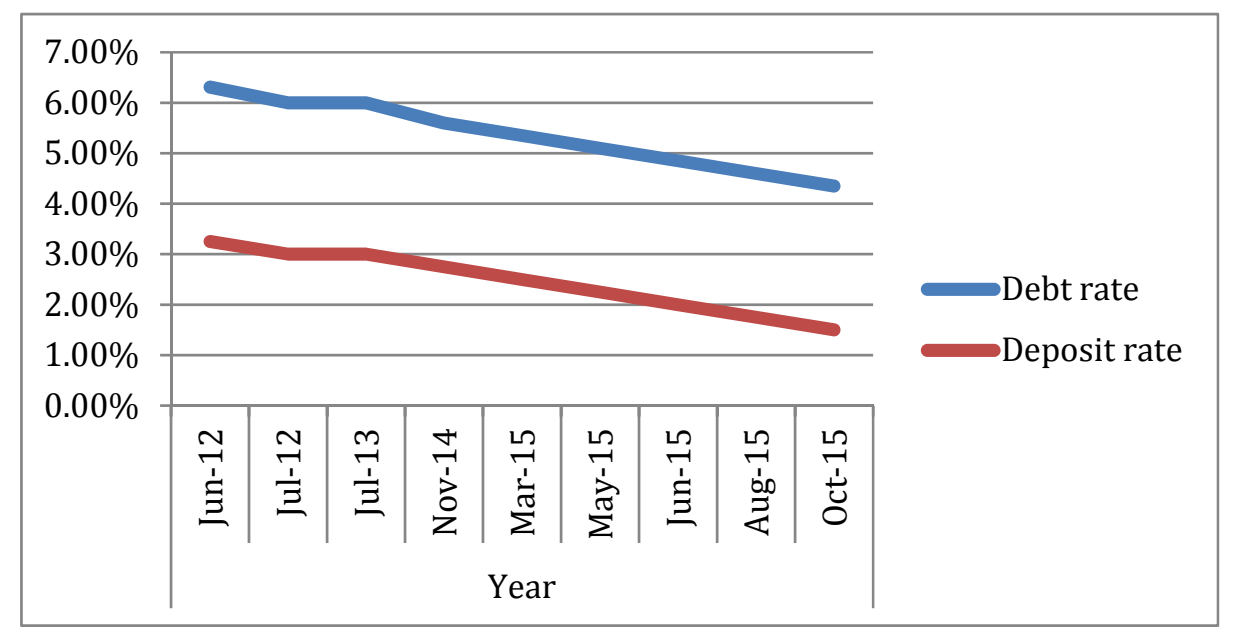

Figure 1. The change of one-year debt and deposit rate from 2012 to 2016

The data in the figure below are all based on four banks' annual report from 2012 to 2016 to conduct empirical analysis. From the chart, it was significant that all the figures in sensitive gap were positive and showed an upper trend in five years. It showed that when facing the change of interest rate, most commercial banks cannot adjust the structure of the assets and liabilities and management the capital gap as soon as possible. The sensitive gap in ICBC and BOC was higher than that in $\mathrm{CMB}$ and $\mathrm{CMBC}$, which meant that the gap in state-owned commercial banks was higher than that in small and medium-sized commercial banks. If the market interest rate rose, the state-owned bank would gain more net interest income. However, if the market interest rate decreased, the small and medium-sized bank would undertake more interest rate risk.

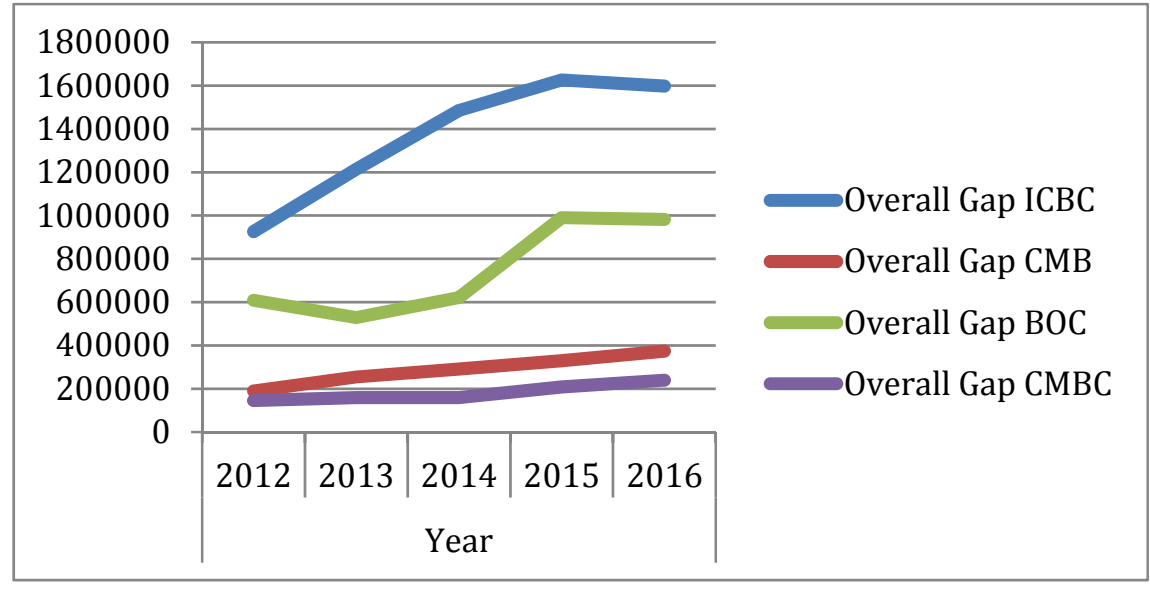

Figure 2. The overall one-year interest rate sensitive gap of four commercial banks from 2012 to 2016 
The figure above also displayed that both ICBC and BOC's sensitive gaps reached their peaks in 2015. ICBC listed at the largest number in special, at 1626241, and then had a slight downtrend between 2015 and 2016. This indicated that ICBC reacted more slowly than other three banks to the decrease of interest rate. It could not adjust the structure of assets and liabilities in time to avoid interest rate risk. BOC was the only bank that decreased sensitive gap in 2013, which indicated that it began to realize the interest rate risk. Despite that, banks were still poor at predicting the future trend of the interest rate. Their attitude towards the interest rate risk was conservative rather than offensive.

On the other side, the small and medium-sized banks' data of sensitive gap maintained at a relatively low position without exceeding 400000 no matter how fluctuate the interest rate was. This meant that the flexibility of joint-stock banks was higher than state-owned banks. They could react quickly and reallocate the assets and liabilities in time in order to adjust their interest rate sensitive gap. The trend of CMBC's sensitive gap was quite same as the trend of CMB's sensitive gap. Comparing to other three banks, the figure of CMB gap was positioned at the lowest part. The risk management in joint-stock banks was stronger than that in big banks.

\section{Conclusion and recommendation}

To sum up, the research has analyzed the risk level and control ability of commercial banks in China under the interest rate marketization. It can be concluded that through the research, the risk level of the stated-owned commercial bank like ICBC and BOC are much higher than that of the small and medium-sized bank like CMB and CMBC. Among them, ICBC has the highest sensitive gap, while CMBC has the lowest sensitive gap. Moreover, the high sensitive gap makes stated-owned banks difficult to control the risk, but small and medium-sized banks have the stronger ability on evading interest rate risk because they can react quickly to the change of interest rate. For recommendations, commercial banks are suggested to change business structure and applying income diversification method by reducing the reliance on deposit and loan service, speeding up financial innovation, adjusting business structure, and enlarging business areas. In addition, interest rate risk measurement model is the core of interest rate risk measurement system. The feasibility and accuracy of models are directly related to the survival of interest rate risk management in China's commercial banks. 
The innovation of the paper depends on the improved study basing on the previous opinions and uses the latest data. The shortage of this research is that the sensitive gap is a static model which means it does not consider capital's time value and interest rate variation, but it can be solved by using other models which consider the time value such as duration model. Further studies can focus on how to predict the future trend of the interest rate because most commercial banks act passively to the interest rate change.

\section{References}

Aggarwal, R., Jeon, B. and Zhao, X., (2005) Bank Exposure to Interest Rate Risks During Financial Liberalization: Evidence from South Korea, Asia-Pacific Financial Markets, 12(1), pp. 61-90.

Ahmed, A., Beatty, A. and Takeda, C., 1997 Evidence on Interest Rate Risk Management and Derivatives Usage by Commercial Banks, SSRN Electronic Journal.

Anon, 2004 Basel Committee on Banking Supervision, [ebook] Available at: <http://Basel Committee on Banking Supervision> [Accessed 22 Jul. 2017].

Beautler, T., Bichsel, R., Bruhin, A. and Danton, J., 2017 The Impact of Interest Rate Risk on Bank Lending. Swiss National Bank.

Bessler, W. and Geoffrey Booth, G., 1994 An interest rate risk management model for commercial banks, European Journal of Operational Research, 74(2), pp. 243-256.

Cui, X., 2016 The Impact of Interest Rate Marketization on China's Commercial Banks and Its Tactics. Journal of Mathematical Finance, 06(05), pp. 921-929.

DeMasi, J., 2006 Understanding Your Bank's Exposure to Market Risk, Community Banker. 
Drehmann, M., Sorensen, S. and Stringa, M., 2008 The Integrated Impact of Credit and Interest Rate Risk on Banks: An Economic Value and Capital Adequacy Perspective. SSRN Electronic Journal.

Fu, X. and Heffernan, S., 2009 The effects of reform on China's bank structure and performance. Journal of Banking \& Finance, 33(1), pp. 39-52.

Funke, M., Mihaylovski, P. and Zhu, H., 2015 Monetary Policy Transmission in China: A DSGE Model with Parallel Shadow Banking and Interest Rate Control, SSRN Electronic Journal.

He, D., Wang, H. and Yu, X., 2014 Interest Rate Determination in China: Past, Present, and Future, SSRN Electronic Journal.

He, L., Chen, L. and Liu, F., 2017 Banking reforms, performance and risk in China. Applied Economics, 49(40), pp. 3995-4012.

Kero, A., 2013 Banks' risk taking, financial innovation and macroeconomic risk. The Quarterly Review of Economics and Finance, 53(2), pp. 112-124.

Landier, A., Sraer, D. and Thesmar, D., 2015 Banks' Exposure to Interest Rate Risk and the Transmission of Monetary Policy, SSRN Electronic Journal.

Lee, T. and Chih, S., 2013 Does financial regulation affect the profit efficiency and risk of banks? Evidence from China's commercial banks, The North American Journal of Economics and Finance, 26, pp. 705-724.

Liao, W. and Tapsoba, S., 2014 China's Monetary Policy and Interest Rate Liberalization: Lessons from International Experiences. IMF Working Papers, 14(75), p. 1.

Lileikienè, A., 2008 Analysis of Chosen Strategies of Asset and Liability Management in Commercial Banks, ECONOMICS OF ENGINEERING DECISIONS. 
Prasad, K. and Suprabha, K., 2014 Anomalies in Maturity GAP: Evidence from Scheduled Commercial Banks in India, Procedia Economics and Finance, 11, pp. 423-430.

Si, W., 2015 Interest Rate Liberalization in China, SSRN Electronic Journal.

Wang, H., Wang, H., Wang, L. and Zhou, H., 2016. Shadow Banking: China's Dual-Track Interest Rate Liberalization. SSRN Electronic Journal. 